\title{
Atrial Tachycardia by ECG Finding
}

National Cancer Institute

\section{Source}

National Cancer Institute. Atrial Tachycardia by ECG Finding. NCI Thesaurus. Code

C111105.

An electrocardiographic finding of an org anized, regular atrial rhythm with atrial rate between 101 and 240 beats per minute. The P wave morphology must be distinct from the sinus P wave morphology. (CDISC) 